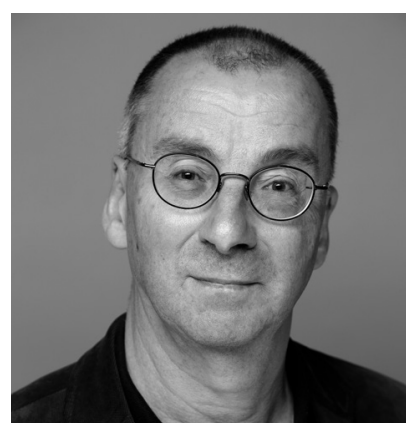

\title{
Transparenz und Hilfe
}

Wohlfahrtsverbände und gemeinnützige Sozialunternehmen leben vom Vertrauen der Menschen in ihre Arbeit. Um dieses immer wieder zu gewinnen und zu sichern, braucht es Offenheit sowohl gegenüber der Öffentlichkeit wie auch nach innen, erläutert Oswald Menninger in seinem Beitrag zu diesem Heft. Die Transparenzstandards wie sie von der Diakonie und der Caritas gemeinsam vereinbart wurden, sind ein gutes Beispiel für die praktische Umsetzbarkeit im Organisationsalltag. Ein weiterer Vorschlag ist der Social Reporting Standard, der ebenfalls in dieser Ausgabe vorgestellt wird. Er will, so die Autoren in dieser Ausgabe, eine »Blaupause« sowohl für das interne Berichtswesen bieten als auch für den Jahresbericht, weil er aufs Wesentliche komprimierte "Wirkungsdaten « mit weiteren Angaben auf einen Blick versammelt: Governance- und Finanzangaben sollen ebenso transparent abgebildet wie Zielgruppen und erzielte Wirkungen. (Das Konzept der »Wirkungsorientierung " wird in diesem Heft übrigens ab Seite 21 kritisch in seinen erfreulichen und weniger erfreulichen Folgen beleuchtet.) Doch bei allen notwendigen und richtigen Bemühungen um Offenheit und Durchschaubarkeit sollte man nicht vergessen, dass der Existenzgrund sozialer Organisationen und Unternehmen nicht in erster Linie die Herstellung von »Transparenz« ist, sondern die Hilfe für Menschen in schwierigen Lebenslagen - darauf gilt es die Kräfte zu konzentrieren.

Die Hefte und Artikel der Zeitschrift SOZIALwirtschaft stehen für Abonnenten der Druckausgabe auch im Nomos-Zeitschriften-Portal (www.nomoszeitschriften.de) online zur Verfügung. Über die Zugangsmöglichkeiten für Privatbezieher und Institutionen informiert Sie Aloisia Hohmann von der Vertriebsabteilung des Nomos-Verlages (hohmann@nomos.de). 